MATEC Web of Conferences 23,01059 (2015)

DOI: $10.1051 /$ matecconf/ 20152301059

(C) Owned by the authors, published by EDP Sciences, 2015

\title{
Thermomechanical analysis of large deployable space reflector antenna
}

\author{
Viktor S. Ponomarev ${ }^{1,2 a}$, Alexander V. Gerasimov ${ }^{1,2}$ and Sergey V. Ponomarev ${ }^{2}$ \\ ${ }^{1}$ Tomsk Polytechnic University, 634050 Tomsk, Russia \\ ${ }^{2}$ Scientific Research Institute of Applied Mathematics and Mechanics of Tomsk State University, \\ 634050 Tomsk, Russia
}

\begin{abstract}
In this article results of large reflector thermal condition forecast using modern numerical simulation methods are presented. The results of thermal analysis are complemented with stress-strain analysis results of the whole structure under thermal loads.
\end{abstract}

\section{Introduction}

Onboard antennas are exposed to extreme temperature fluctuations. The number of thermal cycles and temperature changes depend on the orbit of the spacecraft (SC) and antenna materials. In the case of the geostationary orbit (GEO) shade of the Earth takes place during the March and September equinox, with maximum duration of 72 minutes. The temperature of the material during thermal cycling depends on the orbit parameters, thermo-optical properties (absorption of solar radiation, emissivity and transmissivity), solar angle of incidence, radiative and conductive heat transfer with components of the SC, and the influence of equipment or components that generate heat.

Extreme temperatures from the orbital heating and thermal cycling are dangerous for durability of materials for various reasons [1]. First of all, the main factor is the thermal qualification range over which integrity and properties of the material can be guaranteed. In particular, heterogeneous materials in their close contact, such as composites or surface coating with different coefficients of thermal expansion (CTE) can lead to cracking or peeling when the materials are exposed to significant temperature fluctuations $[1,2]$.

Secondly, properties of materials can depend on the temperature. For example, during the orbital thermal cycling, strength of metals or polymers can be reduced, that will make them more vulnerable to damage. In the design of on-board antennas all these aspects related to thermal effects must be taken into account and materials should be chosen properly. In particular, due to the impact of direct solar radiation, heat transfer in space and the absence of convection in vacuum lead to the extreme

a Corresponding author: vik2rr@gmail.com 
temperatures. Antennas are equipped with thermal control systems to limit the values of temperatures and gradients, and to control the heat exchange with platform and thermoelastic deformations. Passive thermal control device includes a multilayer screen vacuum heat insulation (SVHI), solar reflectors, coatings and paints. The choice of the outer layer of the material is determined by the thermo-optical properties, prevention of gloss, electrical ground, atomic oxygen and protection from micrometeorites.

Another passive thermal protection provided by solar screens and coatings. For example, the emitting surface of the reflector and antenna array protected with sunscreens. Solar screens are thin sheets of radiotransparent material provides at the same time all necessary thermo-optical properties.

\section{Problem formulation}

The aim of thermal analysis is to determine the fields and temperature changes on the elements of the antenna structure in terms of its operation on GEO.

Thermal mode of reflector is determined mainly by solar radiation, additionally due to solar flux reflected from the Earth, by its own infrared radiation of the Earth, and also due to the solar radiation reflected from the structural elements of the spacecraft $[3,4]$.

The finite element (FE) method is widely used to solve the problem of finding the temperature distribution in the structure elements. For each FE drawn heat balance equation of the form [3,5]:

$$
\left(c_{m}\right)_{i} \frac{\partial T_{i}}{\partial \tau}=Q_{i}^{e x t}+Q_{i}^{i n t}+\sum_{j}\left(\lambda \frac{F}{\delta}\right)_{j-1}\left(T_{j}-T_{i}\right)+\sum_{k} \varepsilon_{i} H_{i-k} \sigma\left(T_{k}^{4}-T_{i}^{4}\right),
$$

где $\left(c_{m}\right)_{i}-$ - heat capacity,

$Q_{i}^{\text {ext }}$ - external heat flux on the node $i$,

$Q_{i}^{\text {int }}$ - internal heat generation in the node $i$,

$\lambda \frac{F}{\delta}$ - coefficient determining conductive connection $i$ and $j$ nodes,

$\varepsilon_{i}$ - emissivity of node $i$,

$H_{i-k}$ - surface of the mutual radiative heat exchange between $i$-th and $k$ - $t$ hodes,

$\sigma=5.67 \cdot 10^{-8} \mathrm{BT} /\left(\mathrm{M}^{2} \cdot{ }^{\circ} \mathrm{C}^{4}\right)-$ Stefan-Boltzmann constant.

Thermal mathematical model of the reflector structure includes a finite number of isothermal nodes interrelated with thermal couplings defined by embodiment of the calculation unit. Each node of the thermal model is determined by the heat balance equation. The system of equations, supplemented by the initial and boundary conditions, completely describe the thermal model.

The final model of the solar flux incident on a unit area of structure has the form [4]

$$
Q_{\text {solar }}=A_{s} \cdot S_{\max }
$$

где $A_{s}$ - absorption coefficient of the direct solar radiation, $S_{\max }$ - solar constant, which varies according to Figure 1. 
TSOTR 2015

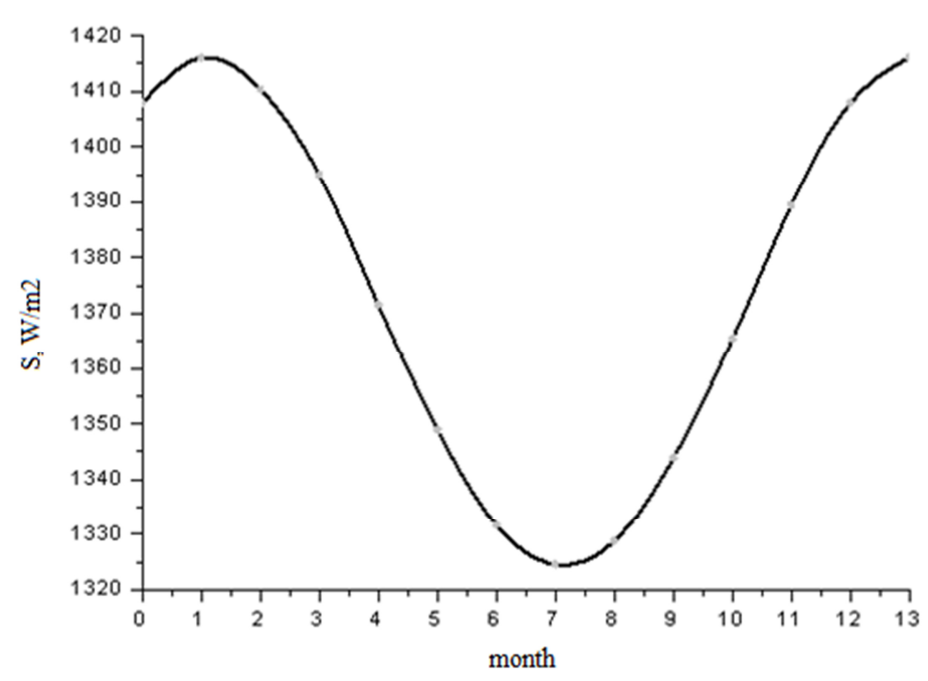

Figure 1. Graph of the solar constant changing throughout the year.

Reflector thermal analysis was carried out for the two extreme cases of orbital inclination (in parentheses the values of the intensity of solar radiation for the case $S_{0}$ are given):

- $\quad$ March equinox $\left(\mathrm{S}_{0}=1380 \mathrm{~W} / \mathrm{m}^{2}\right)$;

- December solstice $\left(\mathrm{S}_{0}=1420 \mathrm{~W} / \mathrm{m}^{2}\right)$.

To solve the obtained system of equations existing standard or special computer programs for numerical simulation of thermal processes such as Siemens NX Space Systems Thermal are used.

For the calculation in the case of the March equinox the shadow from the Earth on a segment of orbit lasting 72 minutes was taken into account [6]. All calculations are performed for period of time of 24 hours with the step on spiral of orbit in 10 minutes.

\section{Description of the reflector FEM}

Finite element model (FEM) of the reflector with mast si performed in the Siemens NX software. To create FEM engineering solid model of the reflector set up in the CAD system CATIA was used. FEM of the reflector (Figure 2) consists of the following components:

- $\quad$ eight spokes, consisting of root, intermediate and end parts "A" and "B". Each spoke is labeled in order to Sp1-Sp8;

- reflector base;

- $\quad$ rigid part, connecting end parts "A" and "B";

- mast;

- solar panels;

- antenna feeders;

- spacecraft. 


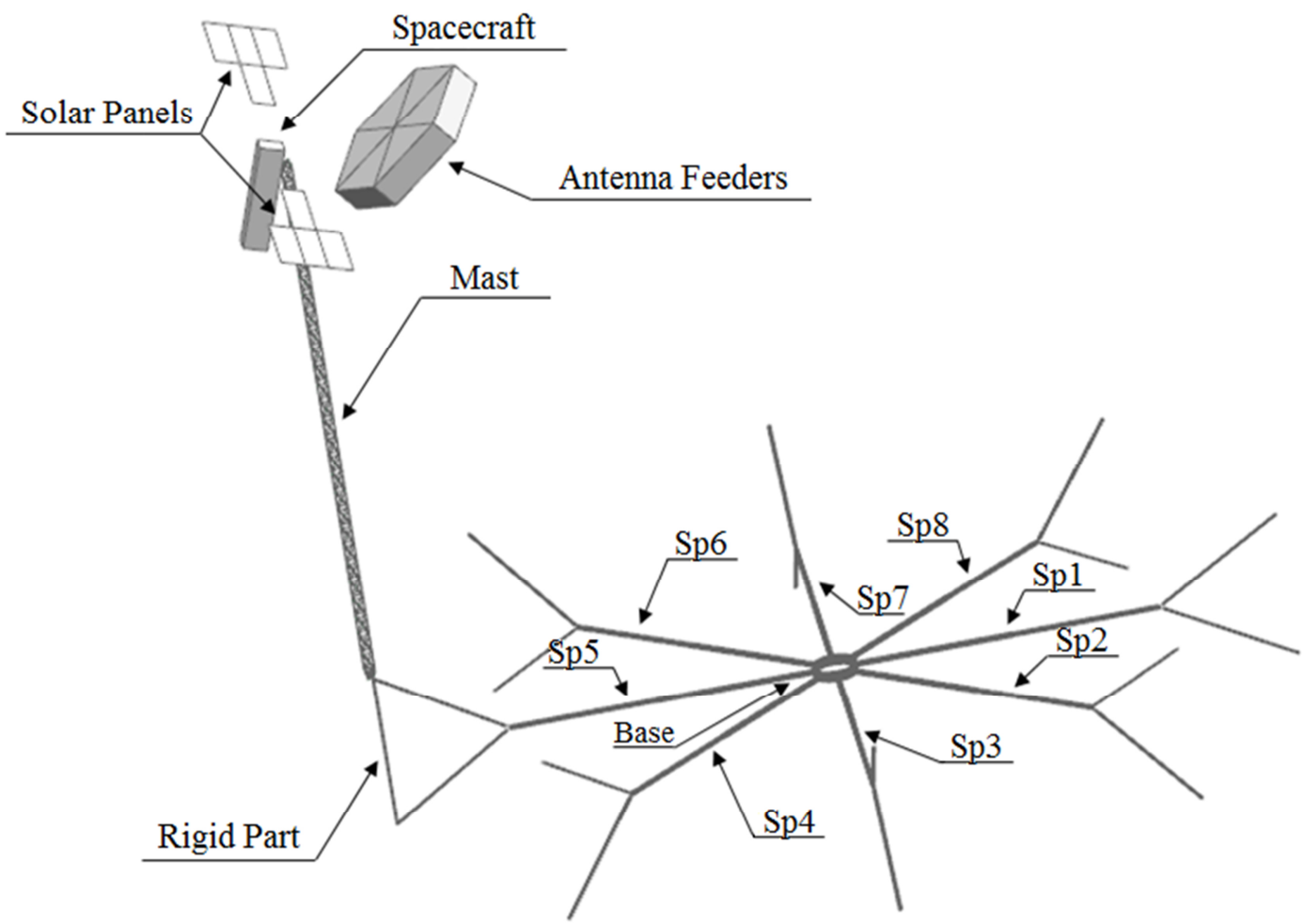

Figure 2. FEM of the reflector with mast.

FEM for thermal analysis (Figure 2) contains 124373 elements and 109476 nodes. The actual distribution of FEM resources for thermal analysis with a description of and assigned material is given in Table 1. The diameter of the reflector 50 meters, root and intermediates parts of the spoke are thinwalled cylinders, cross-section of end "A" and "B" parts is a semi-circle to provide storage inside the intermediate part of the Spoke. FEM of the Spoke in the deployed modification is presented on figure 3. All spokes have the same structure. The mast is a truss structure.

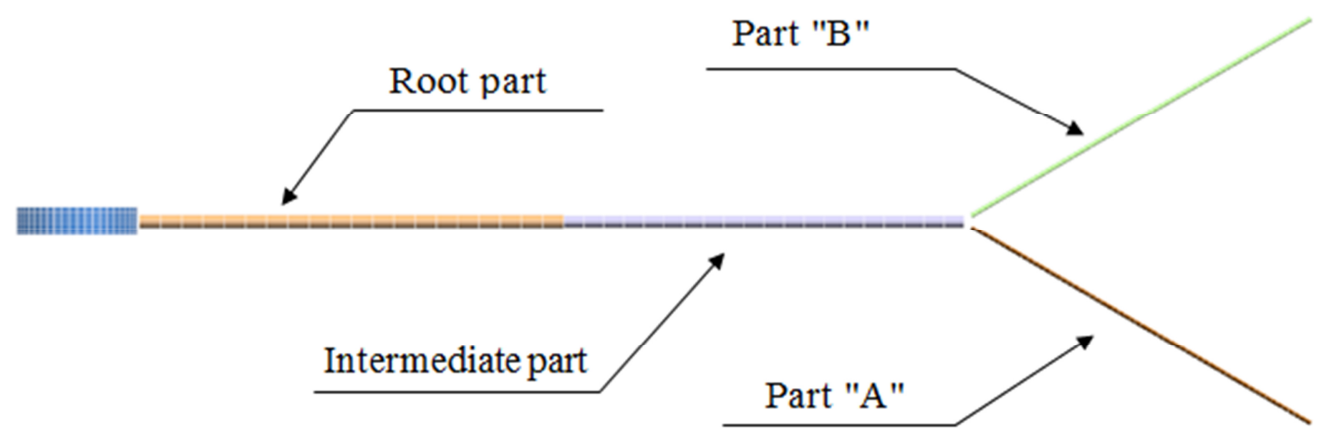

Figure 3. Reflector spoke FEM in deployed state. 
Table 1. FEM resources distribution

\begin{tabular}{|c|c|c|c|c|}
\hline Component & $\begin{array}{c}\text { Assigned } \\
\text { material }\end{array}$ & $\begin{array}{c}\text { Element } \\
\text { type }\end{array}$ & $\begin{array}{c}\text { Number of } \\
\text { elements }\end{array}$ & Number of nodes \\
\hline Reflector base & CFRP & Shell & 960 & 1008 \\
\hline Spoke root part & CFRP & Shell & 3840 & 4032 \\
\hline Spoke intermediate part & CFRP & Shell & 3840 & 4032 \\
\hline Spoke end part "A" & CFRP & Shell & 14400 & 14640 \\
\hline Spoke end part "B" & CFRP & Shell & 14400 & 14640 \\
\hline Mast rod elements & CFRP & Shell & 12560 & 44700 \\
\hline Mast cables & Steel & Solid & 51712 & 14228 \\
\hline Mast fitting & Titan & Solid & 22022 & 600 \\
\hline $\begin{array}{c}\text { Rigid part, connecting end } \\
\text { parts "A" and "B" }\end{array}$ & CFRP & Shell & 624 & 42 \\
\hline \begin{tabular}{c} 
Shadowing parts \\
\hline
\end{tabular} & - & Solid / shell & 15 & \\
\hline
\end{tabular}

\section{Assumptions made in analysis}

- The analysis was carried out excluding the influence of the reflecting mesh surface.

- In the considered model assumptions that the material used for units joining separate parts of the reflector, has a low thermal conductivity, and the geometrical shape of the coupling elements involves a small contact area were made. Therefore, the effect of heat conduction between the following parts of the reflector is not taken into account: the reflector base and spokes root parts; between spokes parts $\mathrm{A}$ and $\mathrm{B}$; spokes intermediate parts and parts $\mathrm{A}$ and $\mathrm{B}$; rigid connecting element and parts $\mathrm{A}$ and $\mathrm{B}$, and between the mast and the $\mathrm{B}$ part of the spoke and the rigid connecting element.

- $\quad$ To simplify the thermal analysis thermal conductivity of CFRP was considered as isotropic and equal to the thermal conductivity along the direction of the fibers.

- Performed analysis is universal for both the beginning and the end for the active shelf life of the SC, as the optical properties of the materials for structural elements considered in the thermal FEM assumed constant.

- The contribution of high-frequency radiation is not taken into account within this model.

\section{Description of the obtained results}

According to analysis results the maximum temperature during the December solstice $\left(131{ }^{\circ} \mathrm{C}\right)$ is achieved at steel cable of the mast. The minimum temperature for the December solstice $\left(-159^{\circ} \mathrm{C}\right)$ are implemented at the root part of the spoke.

Calculations showed that for the March equinox, the maximum value of the temperature $\left(114{ }^{\circ} \mathrm{C}\right)$ is achieved at the steel cable of the mast (at the same node achieved the maximum temperature for the 
December solstice). The minimum temperature of analyzed structure for the March equinox $\left(-200{ }^{\circ} \mathrm{C}\right)$ is achieved at a node on the basis of the reflector.

Obtained from the thermal analysis temperature fields were used as boundary conditions for the structural model of the reflector, and structural analysis of thermal deformations of the reflector on the mast was performed. Using coordinates of the deformed reflecting surface nodes of the reflector the changes in the accuracy of the structure on the GEO were estimated. So the maximum displacement of the focal point of the reflector relative to the initial position for the December solstice is $0.965 \mathrm{~m}$ and for the March equinox - $0.4 \mathrm{~m}$; maximum root-mean-square (RMS) deviation is 5.88 and $4.66 \mathrm{~mm}$, respectively; maximum change of focal length is 8.9 and $10.5 \mathrm{~cm}$.

\section{Conclusion}

Thermal mode analysis of the large-sized reflector structure for the GEO was performed. Analysis results showed that temperature range for the frame structure of the reflector ranges from -200 to $+131{ }^{\circ} \mathrm{C}$.

Also analysis of stress-strain state of the reflector under the influence of thermal loads during the orbital motion on the GEO was done, obtained results are presented below:

RMS: $5.85 \mathrm{~mm}$

Focal point displacement: from 0.085 to $0.965 \mathrm{~m}$

Focal length: from 31.7 to $32.1 \mathrm{~m}$

\section{References}

1. Ning Hu. Composites and Their Applications. (2012)

2. A.C. Long. Composites forming technologies. (2007)

3. V.S. Ponomarev, A.V. Gerasimov, S.V. Ponomarev, D.O. Shendalev. EPJ Web of Conferences. 82, 01005 (2015)

4. A.A. Yashuk. modelirovanie, algoritmy i paket programm prognozirovaniya termomexanicheskogo povedeniya krupnogabaritnogo zontichnogo reflektora: dis. ... kand. fiz.mat. nauk: 05.13.18 (2005)

5. G.P. Kobranov, A.G. Tsvetkov, A.I. Belov, V.A Sukhiyev. Vneshniy teploobmen kosmicheskikh obyektov. (1977)

6. D.G. Gilmore. Spacecraft Thermal Control Handbook. Volume 1: Fundamental Technologies. (2002) 